\title{
ANOTACIONES CLÁSICAS Y CRISTIANAS A UN SONETO DE LOPE ( ¿QQUÉ TENGO YO QUE MI AMISTAD PROCURAS?»)
}

\author{
antonio Ramajo Caño
}

1. Cristóbal Cuevas ha mostrado en un excelente trabajo cómo el soneto de Lope al que nos vamos a referir debe insertarse en la tradición hispana de la «ronda del galán», vuelta a lo divino': Cristo ronda al alma y le pide que le deje entrar en su casa. Y, desde luego, después de la atinada erudición que allí se expone resulta difícil no admitir que bien pueda ser ésta la senda en la que se inserte el famoso soneto lopesco. Con todo, y sin negar la explicación de Cuevas, nos tienta la idea de que acaso en estos versos, además de esa huella hispana, se encuentre un viejo topos clásico, ciertamente, vuelto a lo divino. Se trata del venerable paraclausithyron, del que ahora daremos unos mínimos datos para situar nuestro posterior comentario.

1 Cf. «El tema sacro de La ronda del galán (¿Fray Luis fuente de Lope?)», Academia Literaria Renacentista. I. Fray Luis de León (Salamanca, Univ., 1981), 147-69. Cf. p. 68, en la que hace un resumen de su tesis: «...existe en la literatura espiritual cristiana de todos los tiempos, y (...) en la española del Siglo de Oro, una tradición que enfoca la llamada a la conversión y a la penitencia desde la perspectiva de la ronda del galán». Por otro lado, en su trabajo Cuevas matiza las afirmaciones que sobre el influjo de Fray Luis de León en este soneto de Lope había hecho R. LAPESA, «Presencia de Fray Luis en el soneto de Lope "¿Qué tengo yo, que mi amistad procuras?" ", Poetas y prosistas de ayer y de hoy (Madrid, Gredos, 1977), 178-85. 
El paraclausithyron consiste en el lamento expresado por el enamorado, ante la puerta, infranqueable para él, de la amada ${ }^{2}$. Plutarco fue el primero que utilizó tal término ${ }^{3}$. Lucrecio, a su vez, se referirá al tema con la expresión exclusus amator ${ }^{4}$. Es topos muy reelaborado en la literatura griega y latina. Horacio, concretamente, lo recrea varias veces ${ }^{5}$. Y, sin duda, él, en éste como en tantos otros temas, sirve de portavoz transmisor para la posteridad. Precisamente, en la lírica española, encontramos frecuentes versiones o adaptaciones de una de las odas horacianas en que aparece nuestro topos, la número 10 del libro III, que comienza «Extremum Tanain si biberes, Lyce» ${ }^{6}$. En efecto, nuestros poetas se

2 Cf. la definición de F. O. Copley: «The paraclausithyron is the song sung by the lover at his mistress's door, after he has been refused admission to her house', Exclusus Amator. A Study in Latin Love Poetry, American Philological Association Monographs, 17 (New York, 1956), p. 1.

${ }^{3}$ Cf. Henderson, W. J., "The Paraklausithyron motif in Horace's odes», Acta Classica, 16 (1973), $51-67$ (p. 52, nota 9). Véase el texto de Plutarco en la ed. de M. Cuvigny (Paris, «Les Belles Lettres», 1980), t. X, p. 59.

4 Cf. Henderson, 52, y nota 9.

5 Cf. Henderson, 52 ss.

6 Un comentario de esta oda horaciana podrá encontrar el lector en la obra de Copley, ya citada, pp. 62 ss.; en la ed. de A. KIEssLing, Oden und epoden (Berlin, 1930), 304-08; en la de K. QUINN, The Odes, reimpr. (Hampshire, Macmillan Education, 1984), 262-64. Para la huella de Callímaco, cf. A. THILL, «Alter ab illo*. Recherches sur l'imitation dans la poésie personnelle à l' époque augustéenne (Lille, Université, 1976), I, 299-300.

En este poema horaciano el tema ocupa los ocho primeros versos -y reaparecerá, según veremos, en los dos últimos-. En aquéllos se habla de las inclemencias del tiempo: el furor de los Aquilones, v. 4; la nieve y el hielo, v. 7. Y el amante, según es frecuente, aparece echado a la puerta de la amada:

*Extremum Tanain si biberes, Lyce, saevo nupta viro, me tamen asperas porrectum ante foris obicere incolis plorares Aquilonibus.

Audis quo strepitu ianua, quo nemus inter pulchra satum tecta remugiat ventis, et positas ut glaciet nives

puro numine luppiter?"

(Citamos siempre por Horace, Odes et Epodes, ed. de F. Villeneuve. 9." ed., París, «Les Belles Lettres", 1970, p. 117).

Luego viene una súplica de diez versos, para que Lyce deponga su dureza amorosa, y se torna al tema, de manera humorística, en los dos últimos versos: «non hoc semper erit liminis aut aquae/ caelestis patiens latus» (vv. 19-20).

7 Nos referimos al siguiente soneto:

"Aunque pisaras, Fili, la sedienta arena qu'en la Libia Apolo enciende, sintieras, ;ai!, que el Aquilón me ofende, $i$ del yelo i rigor la pluvia lenta.

Oye con qué riiido la violenta furia del viento en el jardín s'estiende, 
han sentido atraídos por este bello poema horaciano. Lo atestiguan, al menos,

i que apena aun la puerta se defiende

del soplo que en mi daño se acrecienta.

Pon la soberbia, ô Fili, i blandos ojos

muestra. pues ves en lágrimas bañado

el umbral que adomé de blanda rosa;

que no siempre tu ceño i tus enojos

podré sufrir, ni el mustio ivierno elado,

ni del Bóreas la sara $\mathrm{q}$ impetuosa».

(Es el núm. 10 en la ed. de Begoña López Bueno, Francisco de Rioja, Poesía (Madrid, Cátedra, 1984), p. 148.)

Cf. M. Menéndez PElayo, Horacio en España, en Bibliografía hispano-latina clásica (Madrid, CSIC, 1951), VI, p. 330. Cf. también Vicente Cristóbal, Horacio, Odas y Epodos, en colaboración con M. Fernandez-Galiano (Madrid, Cátedra, 1990), comentario a III, 10.

Puede decirse que Rioja ha sabido transplantar bellamente al castellano el poema de Horacio. El soneto le ha servido de marco propicio para la contención, algo fundamental a la hora de enfrentas elementos los versos del venusino. Nótese la bien medida distribucion: el fuerte viento, la helada, la lluvia; el pricircunstanciales frecuentes en la lica que Horacio dirige a Lyce; por fin, el segundo terceto muestra la flaqueza futura del amante, si la muchacha no se pliega a sus deseos. Notemos ahora, con más pormenor, cómo Rioja es fiel a Horacio, y señalemos también sus desajustes con el modelo original.

Nuestro poeta sitúa la escena amorosa, no en la Scitia, sino en Libia. Ello le lleva a caer en una cierta contradicción. Por un lado, el soneto nos habla, con encabalgamiento incluso, de la sedienta arena, algo coherente con el territorio escogido, pero, a clementos climáticos más propios del aparece el Aquilón, viento frío del norte, la plú territorio que el poeta latino había seleccion es es estrecha: en poeta vierte los versos originales con gran cercanía: Oye con qué rüido la violenta furia del viento en el jardín s'estiende, equivale con bastante proximidad a Audis... quo nemus/ inter pulchra satum tecta remugiat ventis. Con orden cambiado, los dos versos finales del cuarteto segundo se acomodan a los dos primeros de la segunda estrofa horaciana. Pero aquí Rioja no se ha ceñido al original. El poeta latino decía simplemente: Audis quo strepitu ianua (remugiat]; Rioja amplifica: I que apena aun la puerta se defiend que el poeta español mi daño se acrecienta. Claro que este verso final del cu que se aprecia también en los versos 12-13: ha querido dar un tono más intimista a sus verse, en los que se ofrece novedad con respecto a Horaque no siempre tu ceño i tus enojos podre sucraz de soportar en el futuro los embates de la naturaleza, cio, quien nos presentaba a un ama padecer los propios desdenes de la amada. Pero volviendo atrás, sin mencionar la imposibilider terceto resume con eficacia la súplica horaciana que se extiende en diez versos. Además, aquí Rioja se aparta bastante del original. Traduce, sí, fielmente el pone superbiam por pon la soberbia. Pero, luego, se distancia de Horacio, y con acierto, a nuestro juicio. Hubieran acaso quitado aquí eficacia expresiva el respetar la alusión mitolón al carácter etrusco inclinado al exempla constituyan un rasgo característico de Horacio), la arions. vv. 11-12); o el ser fiel a los reiamor (...non te Penelopen difficilem procis Tresenta la dureza de la mujer cantada ( $O$ quamvis neque terados rasgos con que el poeta latino nos premantium/ nec vir Pieria paelice saucius/ curvat, supt' munera nec preces/ nec tinctus viola pallor amo/ nec Mauris animum mitior anguibus..., vv. 13-18). plicibus tuis/ parcas, nec rigida mollior aesculo/ nec Mauris animum mitior anguibus..., vv. 
Francisco de Rioja ${ }^{7}$, Pedro Soto de Rojas ${ }^{8}$ y Villegas ${ }^{9}$, sin mencionar a aquellos otros que más que imitar se limitan a traducir ${ }^{10}$.

Bastan tres versos a Rioja para expresar la misma idea. Con el mandato $i$ blandos ojos/ muestra, nuestro poeta se instala, por otro lado, en una tradición lírica del XVI y del XVII, en que la mirada queda extraordinariamente resaltada en el diálogo amoroso. Por eso Aldana deseaba «los ojos contemplar que de contino/ engendran paz, quietud, guerra y recelo?» (Poesias, ed. de E. L. Rivers, Clás. Castellanos, 143, Madrid, 1966, soneto IX, vv. 119-20, p. 8). El poder de la mirada es una y otra vez cantado por los poetas. Para Herrera, la luz de los ojos «sereno dexa el ayre, alegre el suelo» (Rimas inéditas, ed. de J. M. Blecua, Madrid, CSIC, 1948, soneto V, v. 4, p. 43). Sin duda, Petrarca queda en la lejanía: «e que'belli occhi che i cor fanno smalti $/$ possenti a rischiarar abisso e notti, $/ \mathrm{e}$ tôrre l' alme a' corpi, e darle altruin (Obra completa en poesía. El Cancionero, ed. bilingüe de Atilio Pentimalli, Barcelona, 1977, t. II, p. 36, n. 213, vv. 9-11).

$Y$, saliendo de esta digresión y retomando el centro de nuestra exposición, Rioja concluye el soneto con tres versos que en parte ya hemos comentado. En los dos últimos acomoda, sin fidelidad literal, otros dos horacianos: non hoc semper erit liminis aut aquae/ caelestis patiens latus. Lamento no haber podido consultar la edición de Gaetano Chiappini (Firenze, Università, 1975).

${ }^{8}$ Es el poema titulado *Noche de Inviemo en su puerta», que comienza:

«Aunque de mármol fuera

tu pecho siempre de aspereza armado,

lastimarse pudiera

del que a tu puerta echado

sufre el ceño del cierço delicado. (...) (Vv. 1-5.)

Y concluye:

*O piedra, siempre elada!

hazle a tu tiranía resistencia,

oye mi voz cansada,

que no siempre, en tu ausencia,

podré sufrir del cielo la inclemencia»

(vv. 31-50, en Desengaños de amor en rimas, Madrid, 1623, ed. de A. Gallego Morell, Pedro Soto de Rojas, Obras, Madrid, CSIC, 1950, pp. 99-100).

Ya había notado esta fuente MENéndez PELAYo, Horacio, p. 100.

9 El tema del paraclausithyron fluye a lo largo de los sesenta y seis versos del poema n. ${ }^{\circ} 16$ de Villegas, según la ed. que citamos infra (veinte versos tenía la oda de Horacio). De manera que aquello que en el poeta latino era elemento integrante del poema -importante, desde luego- se convierte aquí en el gozne vertebrador de los versos. Pero, además, en Horacio, humorísticamente, el amante no parecía dispuesto a resistir in aetermum las inclemencias del tiempo; en cambio, aqui el poeta tiene fuerzas para permanecer siempre a las puertas de la amada. Desde el alba ( $\propto \mathrm{Al}$ respetado mármol de tu puerta me ve la blanca aurora...m, vv. 13-14) el amante permanece junto a la puerta querida. No hay obstáculo que lo aparte. Villegas no sólo se aleja del espíritu horaciano original, sino que el gusto por la amplificatio convierte el poema castellano en un producto extraño al espíritu del venusino. Incluso Villegas, para intensificar su expresión del apego a los umbrales de la amada, se permite imaginar acontecimientos que Horacio no podría mencionar, acontecimientos que acaso sucedan, con ser improbables. Lo que no sucederá, en verdad, es el desvío del poeta:

"Que primero los duros escuadrones

de César no vencido

adorarán los bárbaros pendones.

y al Persa inadvertido 
Pero, volviendo ya al soneto de Lope, nada se opone a la consideración de que nuestro poeta tuvo presente, además del tema hispano vuelto a lo divi-

\author{
rendirán el denuedo, \\ o al engañoso retirar del Medo» \\ (Eróticas o Amatorias, ed. de N. Alonso Cortés, Clás. Castellanos, 21, Madrid, 1956, n. 16, vv.
} 36-42, p. 32).

En esta línea termina el poema de Villegas. Si Horacio amenazaba con no ser fiel a Lice, nuestro poeta suplica y promete firmeza:

«Muévate ver un miserable amante

sujeto a la aspereza

del Aquilón y Céfiro sonante;

muévate mi firmeza,

pues será sostenida

mientras durare la firmeza en Lida»

(vv. 61-66, ed. cit., pp. 32-33).

Para el influjo de Horacio en Villegas, cf., aunque sea incompleto y no se refiera al poema comentado, V. BoccheTTA, Horacio en Villegas y en Fray Luis de León (Madrid, Gredos, 1970).

Todavía quedan en nuestra lírica otras manifestaciones de este topos, pero con alguna particularidad. Lupercio Leonardo de Argensola integra el tema (acaso no se inspire precisamente en la Oda III, 10) dentro del Soneto que comienza Si quiere Amor que siga sus antojos. Si el poeta volviera a ser joven, podría amar a Filis:

«Y entonces, como sierpe renovada,

a la puerta de Filis inclemente

resistiré a la lluvia y a los vientos.»

(Vv. 9-11, en Rimas, ed. de J. M. Blecua, Clás. Castellanos, 173, Madrid, 1972, p. 68).

Su hermano Bartolomé también se ejercita en el tema del paraclausithyron y se inspira precisamente en la oda III, 10 de Horacio, pero la dota de un contenido fuertemente satírico. He aquí el soneto al que nos referimos:

«A las puertas de Lice está tendido

Clito, sin atender si es excelencia, sufriendo de los cielos la inclemencia, por blando lecho el suelo empedernido.

No le despierta, con que se ha reído

la Aurora (pienso) viendo su presencia; y acelerando el paso, jcruel sentencia!, llamó al Sol que lo viese así dormido.

¡Oh juventud lozana, penitente en mentiroso traje de milicia, imitadora de la edad antigua!

¿Son éstos tus Scipiones? ¡Pero, tente;

que es lástima de oírlo, y no es malicia decir que no son más que una estantigua.»

(Rimas, ed. de J. M. Blecua, Clás. Castellanos, 184-85, Madrid, 1974, t. II, p. 195).

10 Citemos los casos de Fray LUIS DE LEON - véase el texto en Obras completas castellanas, ed. del P. Félix García, 4." ed., (Madrid, BAC, 1967), II, p. 940-, y de Francisco MEdrano, «Ode» IX, en Poesía, ed. de D. Alonso (Madrid, Cátedra, 1988), 215-16. 
no ${ }^{11}$, el paraclausithyron aludido. Releamos los seis primeros versos, en los que se encuentra la posible huella:

11 El tema de la ronda del galán a lo divino aparece, desde luego, en José de VALDivieso (algo que ya había apuntado M." R. LIDA, quien se refiere también a Lope, sin especificar el texto, en *Transmisión y recreación de temas grecolatinos en la poesía lírica española», Revista de Filología Hispánica, 1959, 20-63, recogido en La tradición clásica en España, Barcelona, Ariel, 1975, 37-99 [cf. p. 68]). En efecto, José de Valdivieso, en «Letra al Niño Jesús», recoge el tema del amante que espera a la puerta de la amada. Aquí ese amante es el Niño Jesús.

«Entra mayo y sale abril;

¡cuán garridico me le vi venir!

Hízose mayo encamado

el Niño Jesús que adoro,

y entre el pelo rizo de oro,

de hermosas flores cercado.

Como un mayo enamorado,

al alma viene a servir;

¡cuán garridico me le vi venir!

Hecho ya un florido mayo,

por si su Esposa despierta,

quiere plantarse a su puerta

por dar vida a su desmayo;

estrecho le venía el sayo,

y en Belén se le hizo abrirn. (...)

(Vv. 1-8, Romancero espiritual, Pról. del P. Miguel Mir, Madrid, Impr. de Pérez Dubrull, 1880, p. 227. Lo reproduce J. M. BLECUA, Poesia de la Edad de Oro. II Barroco, Madrid, Castalia, 1984, p. 45.)

Como es obvio, Valdivieso recrea aquí un muy conocido poema perteneciente al grupo de las canciones llamadas mayas, que ahora recordamos:

«Entra mayo y sale abril,

tan garridico le vi venir.

Entra mayo con sus flores,

sale abril con sus amores,

y los dulces amadores

comienzan a bien servir.»

(Citamos por Poesía española medieval, ed. de M. Alvar (Barcelona, Planeta, 1969), p. 969.)

VÉase también del mismo Valdivieso el siguiente «Romance del esposo, quejándose a la esposa»:

«Despertad, alma dormida,

la que en las culpas dormís, que el alma que a su esposo ofende no es justo que duerma ansí.

Abrid esas celosías, ya que las puertas no abrís, y por vos me veréis tal. que no parezco al que fui.

Por rondaros, alma mía, rebozado vine aquí, y aunque me asió la justicia. no me quise descubrir. (...)»

(Vv. 1-12, Romancero, p. 117). 
«QQué tengo yo que mi amistad procuras?

¿Qué interés se te sigue, Jesús mío, que a mi puerta cubierto de rocío

pasas las noches del invierno escuras?

¡Oh cuánto fueron mis entrañas duras, pues no te abrí!... ${ }^{12}$.

¿Cuáles son los elementos del tópico clásico en estos versos? Enumerémoslos: naturalmente, la puerta cerrada, la obstinación de la persona que se encuentra dentro de la casa y la larga y fría noche ${ }^{13}$. Cierto que caben posibles objeciónes. Así, el amante, Cristo, no se lamenta de los desdenes de la amada. Parece, pues, que falta uno de los elementos fundamentales del tópico. Sin embargo, ello no nos desanima en la exposición de nuestra tesis. No sólo porque no siempre se manifestara el lamento en el tratamiento clásico del tema (sabemos que en Ekklesiazusai de Aristófanes aparece el amante tendido ante la puerta, pero $\sin$ lamentarse) ${ }^{14}$; sino porque las quejas no tienen que estar necesariamente explícitas. Pero es que, además, en otro texto de Lope que se suele citar siempre como ilustración de nuestro soneto, pues en él reaparece el mismo tópico, encontramos al amante, Jesús, que suspira ante los desdenes del alma. Reproduzcámoslo:

Véase un último ejemplo:

\&La puerta me ronda

mi amado esposo:

lindo cuerpo tiene,

su gracia adoro».

(Vv. 1-4 de «Seguidillas al Santísimo Sacramento», Romancero, p. 201. Reproducido en Corpus de la antigua lírica popular hispánica (siglos XV a XVII), ed. de Margit Frenk, Madrid, Castalia, 1987, p. 650. Y en Cancionero tradicional, ed. de José M." Alín, Clás. Cash 1991, p. 448.)

12 Rimas sacras, 1614, vv. 1-6. Citaremos siempre por: LOPE DE VEGA, Poesía selecta, ed. de Antonio Carref̂o (Madrid, Cátedra. 1984, p. 326).

13 Henderson, «The Paraklausithyron», p. 53, enumera los motivos del tema que aparecen ya en la Antología Palatina, a saber: puertas, guimaldas, lagrimas, inclemencia del tiempo, amenazas, rótulos en la puerta o en la guirnalda, larga y fria noche, obstinada muchacha, lamento. Claro, todos esos elementos no podrán manifestarse en una sola producción literaria.

Para el influjo de Horacio en Lope de Vega, cf. M. MEnéndez Pel.ayo, Horacio en España, 349-53 (no trata del aspecto que comentamos aquí).

14 Vid. Ekklesiazusai, 938-75. Cf. HeNDERSON, «The Paraklausithyron», p. 52. 
«Dulcísimo Jesús, yo estaba ciego,

yo estaba ciego, vida de mi vida,

pues no te abrí cuando llamaste luego...

¿Es posible, mi Dios, que no te oyese

Francisco cuando tú dabas suspiros

por que la puerta a tu hermosura abriese?

Vida del alma, yo sentí tus tiros

en mi cama acostado alguna noche

y no dije: Señor, ya salgo a abriros...

Tú los inviernos en mi calle, helando

tu regalado cuerpo, y yo durmiendo,

muerto y amortajado en lienzo blando!...»15.

Todavía nos queda otra posible objeción a la afirmación de haber encontrado huellas del paraclausithyron en el soneto de Lope. En el tema clásico, la voz que vertebra el texto literario parte del amante que se encuentra en la puerta, fuera de la casa de la amada; aquí, sin embargo, la perspectiva es diferente. El alma, la amada, dentro de la casa, realiza la «narración» de los amores. Creemos, con todo, que tal cambio de perspectiva no constituye una verdadera objeción. Sin duda, el esquema utilizado por Lope conviene a su particular propósito: mostrar su arrepentimiento, su personal aflicción. Ciertamente, si resulta posible que un tópico profano se vuelva a lo divino, ¿no habrán de modificarse las "voces" enunciadoras del poema, cuando la propia intención del poeta así lo exija? Sí, Lope quería mostrar la aflicción de su alma ante los desvíos cometidos hacia un amante siempre apasionado; y convenía que fuera el alma, quien

15 Soliloquio de El serafín humano (act. IV), comedia citada en el segundo Peregrino, anterior, por tanto, a 1618. Apud LoPE DE Vega, Poesías líricas, ed. de José F. Montesinos, Clás. Castellanos, 68, reimpr. (Madrid, 1968), t. I, p. 158, nota 1.

Esta posición nuclear de Cristo en una piedad cimentada en el pathos del arrepentimiento viene de unos años antes. En esa tradición. Cristo siempre es el amante lleno de ternura, que se queja de los desvíos del alma. No vamos a seguir aquí su estela. Solamente, como ilustración, citaremos unos versos de Sebastián de Córdoba, en su Garcilaso a lo divino. En la Egloga primera, Cristo «del ánima se quexa, y sus amores $/$ que en vanas afectiones va empleando" (la ed. original es de 1575, Granada. Citamos por la ed. de Glen R. Gale, Madrid, Castalia, 1971, vv. 5-6, p. 157). Es, pues, un Cristo amante del alma el que nos presentan los poetas, que, incluso, pasa la noche a la espera de encontrar un gesto amoroso. Y todo lo hace el poeta para provocar el arrepentimiento en el alma del lector, a la vez que él mismo se arrepiente.

Por otro lado, lo que acabamos de decir hay que insertarlo en el clima de incremento de la afectividad en la lírica del siglo XVII. Cf. A. EGIDo, «La Hidra bocal. Sobre la palabra poética en el Barroco», Edad de Oro, VI (1987), 79-113. Reproducido en su volumen Fronteras de la poesia en el Barroco (Barcelona, Crítica, 1990), 9-55 (cf. pp. 49-50). 
hablara, pues este soneto constituye una confesión - modalidad que se adapta perfectamente al deseo de Lope de provocar una fuerte conmoción en el lector, muy del gusto del Barroco, por otro lado-, confesión que, aunque probablemente fuera sincera, puede engastarse en la convencionalidad de un topos largo tiempo utilizado ${ }^{16}$. Y Cristo, en el soneto, apasionado frente a un alma fría, ahora arrepentida, se convierte en elemento provocador del pathos.

2. Si Lope, en los seis primeros versos, puede tener huellas de un tema clásico, vuelto a lo divino, acaso suceda lo mismo en el primer terceto. Recordemoslo:

« Cuántas veces el ángel me decía:

"Alma, asómate agora a la ventana,

verás con cuánto amor llamar porfia"!»

En las palabras del ángel hay una invitación al arrepentimiento. Parece como si en ellas sonara el viejo tema del carpe diem vuelto a lo divino. Si Horacio, y otros poetas, recomendaban aprovechar bien el tiempo para disfrutar de la vida, en el pensamiento cristiano surge la necesidad de convertirse rápidamente, pues se desconoce el futuro, y en él no se puede confiar. Nos vienen a la mente las palabras exhortatorias de Tomás de Kempis:

«Surge et in instanti incipe, et dic: Nunc tempus est faciendi; nunc tempus est pugnandi; nunc aptum tempus est emendandi» ${ }^{17}$.

16 Sobre esta poesía confesional y, en definitiva, sobre la relación vida-literatura en LoPE, cf. ahora Yolanda Novo, «Erlebnis y Poesis en la poesía de Lope de Vega: el ciclo de arrepentimiento y las Rimas Sacras (1614)», Boletin de la Biblioteca de Menéndez Pelayo, 67 (1991), 35-74 (cf., sobre todo, p. 37). Cf. también el art. cit. de A. Egido, p. 50. Las dos autoras reconocen la base biográfica subyacente en la poesía lopesca; lo cual no constituye óbice para que tales elementos biográficos se ahormen en fórmulas literarias bien definidas en la tradición.

17 De imitatione Christi (Matriti, Typographia Regia, 1764), lib. I, cap. 22, 5, 67-68. Carreño, ed. cit., p. 326, nota 13, recoge la opinión de J. M. BLECUA (Obras poéticas de Lope de Vega, Barcelona, Planeta, 1969, I, p. 325, nota 1), según la cual nuestro poeta se inspira, en estos seis versos finales del poema (véase el segundo terceto en el propio cuerpo del texto), en las Confesiones de San Agustín: «Quamdiu, quamdiu cras et cras? Quare non modo? Quare non hac hora finis turpidinis ineae?» (lib VIII, cap. 12, 28-29). No negamos esta posible influencia. Lo que pretendemos en nues- 
No crea el lector que necesariamente afirmamos que Tomás de Kempis quisiera dar la vuelta al consejo horaciano. Acaso no lo tuvo presente ${ }^{18}$. Lo que queremos indicar, más modestamente, es que en el pensamiento cristiano se formula lo que nos atrevemos a llamar un carpe diem a lo divino, que, acaso, tenga alguna relación, por contraste, con el horaciano, o, al menos, con el pensamiento pagano en él subyacente, pues no solo lo formuló, según hemos dicho, Horacio $^{19}$. Pero ese carpe diem piadoso no triunfa en el soneto. El alma rechaza la invitación del ángel:

tro trabajito es señalar que el topos pertenece, en general, al pensamiento cristiano. Recuérdense estas palabras de San Pablo: «Videtis... quomodo caute ambuletis: non quasi insipientes, sed ut sapientes: redimentes tempus, quoniam dies mali sunt» (Efesios, 5, 15-17; ap. Biblia Vulgata, ed. de A. Colunga et L. Turrado, Matriti, BAC, 1965, p. 1136).

18 No sé (evito ahora el plural de modestia para evitar equívocos) si Tomás de Kempis leyó a Horacio. Y desconozco la familiaridad que tendría con los autores latinos. En una ocasión cita a Ovidio, lib. I, cap. 13, 5. Pero los versos seleccionados tienen un contenido moral muy del gusto de los medievales. Por otra parte, es bien sabido que en muchas ocasiones los autores de la Edad Media acarrean citas de los clásicos sin haberlos leído directamente. Claro que nuestro autor vive entre 1380 y 1471. Cronológicamente no es, pues, propiamente un autor medieval. Pero no podemos entrar aquí en estos deslindes, por lo demás, extraordinariamente delicados. Incidiendo en el aspecto que nos interesa (el conocimiento que de los clásicos latinos tiene Tomás de Kempis), señalemos, por fin, que nada dicen a tal proposito F. A. WRIGHT y T. A. SinCLAIR, en A history of later latin Literature (London, 1969), aunque dediquen al autor las pp. 359-62.

19 Por ejemplo, Tibulo invita a disfrutar del presente, para no tener que lamentarse años después, pues confiesa: «Vidi iam iuvenem, premeret cum serior aetas,/ Maerentem stultos praeterisse dies», Carmina, IV, vv. 33-34, ed. de E. Otón Sobrino (Barcelona, Bosch, 1979), pp. 80-82. Y, desde luego, saliendo de Roma, diremos que el topos tenía lejanos antecedentes. Ya hacia el 600 a. C., Alceo, tan leído por Horacio, recomendaba a Melánipo el disfrute del presente, pues no se libraría de la muerte, meditación e invitación luego tan horaciana. Véanse los dos últimos versos de Alceo, del fr. 38 de E. Lobel y D. PaGe, Poetarum Lesbiorum fragmenta (Oxford, Clarendon Press, 1955), en la traducción de J. Ferraté:

$$
\text { *...es siendo joven, cuando debes }
$$

gozar de lo de aquí que Dios te envía»

(Líricos griegos arcaicos, Barcelona, Seix Barral, 1968, p. 291. No insertamos el original griego para comodidad tipografica).

Sobre esta faceta de Alceo, cf. A. ORTEGA, El despertar de la lírica en Europa, Salamanca, 1974, pp. 104-09. Para la historia del tópico en cuestión, cf. P. GilberT, «Horace et l'Egypte. Aux sources du carpe diem", Latomus, 5 (1946), 61-74 (cf. pp. 70-71, para las huellas de Alceo en Horacio). También cita a Alceo, como fuente, en este aspecto, del poeta latino, H. BARDON, «Carpe diem», Revue des Etudes Anciennes, 46 (1944), $345-55$ (cf. p. 354), aunque no sea éste un trabajo de estudio intertextual.

Sobre distintos tratamientos del carpe diem, cf., en fin, nuestro trabajo «Cultura clásica y cristiana en un poema de Fray LUTS DE LEÓN: De la Magdalena». Studia Philologica Salmanticensia. 7-8 (1984), 303-20 (cf. pp. 314-18). 
« $i$ cuántas, hermosura soberana, "Mañana le abriremos", respondía, para lo mismo responder mañana!».

3. En fin, el soneto de Lope, considerado como confesión de hondas inquietudes religiosas -y nosotros no lo negamos-, se nos muestra complejo, instalado acaso en una antigua tradición de temas clásicos y cristianos. Aquí dejamos, con temor, apuntadas algunas ideas para vertebrarlo en la historia literaria. Nuestro intento tal vez haya sido osado, pero nos urgía formular algunas reflexiones, por si sirvieran, al menos, de discusión. 